\title{
Attitudes of Consumers from the Sarajevo Canton in Bosnia and Herzegovina toward Advertising through Sport among the Frequency of Watching Sports Events
}

\author{
Izet Bajramovic \\ University of Sarajevo, Faculty for Sport and Physical Education, Sarajevo, Bosnia and Herzegovina \\ Gorica Zoric and Bojan Masanovic \\ University of Montenegro, Faculty for Sport and Physical Education, Niksic, Montenegro
}

\begin{abstract}
A B S T R A C T
It is proposed that potential consumers form attitudes based on advertising through sport can influence decisions to purchase a particular advertiser's product. From this reason, it is important to analyse their general attitudes toward advertising through sport among various questions, and this investigation was aimed at gaining relevant knowledge about the attitudes of Sarajevo consumers toward advertising through sport among. The sample included 358 respondents, divided into six subsample groups: consumers, who do not watch sports events at all, then consumers who watch sports events 1-30 minutes, next 31-60 minutes, 61-90 minutes, 91-120 minutes, as well as consumers who watch sports events more than 120 minutes during the typical day. The sample of variables contained the system of three general attitudes which were modelled by seven-point Likert scale. The results of the measuring were analysed by multivariate analysis (MANOVA) and univariate analysis (ANOVA) and Post Hoc test. Based on the statistical analyses it was found that significant differences occur at multivariate level, as well as between all three variables at a significance level of $p=.00$. Hence, it is interesting to highlight that it was found there are significant differences showed up between the attitudes of consumers toward advertising through sport among the frequency of watching sports events. These results are so important for the marketers, mostly due to the reason they can't merge all the potential consumers regarding the frequency they watch the sports events. On the other hand, this is the case in previous investigations and this observation presents relevant information.
\end{abstract}

Key words: Attitudes, Advertising, Sports Events, Sarajevo

\section{Uvod}

Zaključci pionirskih studija iz navedene oblasti koji su objavljeni od strane Bauer-a i Greiser-a (Popović, 2011) i Lutz-a (Klačar, i Popović, 2010) pokrenuli su ideje koje se odnose na činjenicu da stavovi potrošača prema reklamiranju predstavljaju jedan od značajnih faktora koji mogu ojačati efikasnost reklamnih kampanja, uglavnom zbog razloga da kognitivna sposobnost potrošača prema reklamiranju jeste sadržana u njihovim osjećanjima i mislima (Muratović, Bjelica, \& Popović, 2014). Ako se nastavi sa istraživanjem ovog pitanja i ode se mnogo dublje, zanimljivo je da se primjećuje postojanje brojnih studija koje su istraživali stavove potrošača prema reklamiranju, ali većina njih smatra stavove potrošača prema reklamiranju samo uopšteno (Bjelica, i Popović, 2011; Popović, 2011b; Popović, Molnar, i Radovanović, 2011a; Popović, Matić, Milašinović, Jakšić, \& Bjelica, 2015a; Popović, Matić, Milašinović, Hadžic, Milošević, i Bjelica, 2015b; Popović, Matić, Milašinović, Vujović, Milošević, i Bjelica, 2015c). U svakom slučaju, neki od njih su zaključili da su stavovi prema reklamiranju pokazali negativan trend tokom 1960-ih i 1970-ih (Popović, Bjelica, Jakšić, \& Georgiev, 2013; Popović, 2015; Popović, \& Milašinović, 2016), dok su drugi pronašli povoljnije stavove ispitanika u istom periodu (Popović, 2011). Ove nedosljednosti su navele na sumnju da reklamne kampanje koje koriste elemente iz specificnih medijuma utiču na stavove potrošača prema reklamiranju u skladu sa tim (Popović, 2011). Neki autori su vjerovali da je jedan od najrelevantni- jih medija, upravo sport, odnosno sportisti i njihovi timovi, sportski događaji i sportski objekti (Bjelica i Popović, 2011), uglavnom iz razloga sto ovi elementi mogu da utiču na stavove potrošača i naprave značajne oscilacije kod stavova u poređenju sa ostalim elementima (Bjelica, Popović, Jakšić, Hadžic, \& Akpinar, 2014b; Bjelica, i Popović, 2015a; Bjelica, \& Popović, 2015b; Bjelica, Gardašević, Vasiljević, \& Popović, 2016a; Bjelica, Gardašević, Vasiljević, \&Popović, 2016c; Zorić, Mašanović, \& Gardašević, 2017; Gardašević, Zorić, \& Mašanović, 2017; Mašanović, Zorić, \& Gardašević, 2018; Gardašević, Zorić, \& Mašanović, 2018). Iz tog razloga, mnogi istraživaci priznaju sport kao nezavisnu reklamnu platformu koju poslovni subjekti mogu koristiti kako bi prevazisli negativne stavove potrošača prema reklamiranju. Samim tim se postavilo i pitanje, kako posmatranje sportskih događaja utiče na stavove potrošača prema reklamiranju u sportu kao jedan od niza problema sa kojim se nije susretalo mnogo autora do sada (Bjelica, Popović, \& Akpinar, 2014a; Bjelica, Popović, \& Akpinar, 2015c; Bjelica, Popović, \& Akpinar, 2016b; Bjelica, Popović, \& Akpinar, 2017; Mašanović, Zorić, \& Gardašević, 2017; Zorić, Mašanović, \& Gardašević, 2018), a to upravo i jeste cilj ove studije.

\section{Metod}

Populaciju u ovoj studiji su činili studenti sa Univerziteta u Sarajevu koji su u vrijeme anketiranja, imali boravište na terito- 
riji Bosne i Hercegovine, dok je uzorak ispitanika organizovan putem kombinovanja ili raslojavanja, tako da su obrađena različita svojstva navedene populacije i različiti prostori na kojima je ona egzistirala.

Upitnici su distribuirani studentima osnovnih studija u štampanom i elektronskom obliku. Ukupno je prikupljeno 362 upitnika, ali je 4 upitnika bilo isključeno iz analize, budući da nisu bili adekvatno popunjeni, tako da je u istraživanju učestvovalo, ukupno 358 ispitanika (slučajno odabranih studenta sa Univerziteta u Sarajevu). Instrument istraživanja je predstavljao standardizovani upitnik (Popović, 2011) i sastojao se iz dva dijela, generalnih stavova prema reklamiranju u sportu i socio-demografskih karakteristika ispitanika kada je učestalost posmatranja sportskih događaja tokom dana u pitanju. Sistem promjenljivih u ovom upitniku je sadržao tri tvrdnje koje su ispitanici trebali da ocijene prema sedmo-stepenoj Likertovoj skali vrijednosti, kao i šest socio-demografskih karakteristika ispitanika (uopšte ne posmatraju, 1-30 minuta, 31-60 minuta, 61-90 minuta, 91-120 minuta, i više od 120 minuta). Popunjavanje upitnika nije trajalo, u prosjeku vise od 10 minuta a ispitanici su u anketi učestvovali na dobrovoljnoj osnovi. Važno je naglasiti da je anketa bila anonimna i da su svi odgovori bili strogo poverljivi. Vrijedno je napomenuti i da su ispitanici, i pored svega navedenog imali mogućnost da u svakom momentu opozovu svoje učešće u anketi, ali se niko od njih nije na tako nesto odlučio.

Empirijski podaci su analizirani putem statističkog paketa za drustvene nauke (SPSS 20.0), a kao prvi korak, bila je primijenjena deskriptivna statistika kojom su izračunati, prije svega frekvencija, zatim aritmeticka sredina, standardna devijacija, kao i mjere asimetrije (Skewness) i spljoštenosti (Kurtosis) za svaku od tvrdnji. Budući da su se promjenljive u ovoj studiji nalazile na neparametrijskim skalama, radi detaljnijih analiza koje su slijedile, bilo je neophodno da se one, primjenom Blomovog postupka transformišu u skale višeg reda. Zatim su primjenom multivarijatne analize varijanse (MANOVA), univarijatne analize varijanse (ANOVA) i LSD Post Hoc testa, utvrđene razlike u generalnim stavovima ispitanika prema reklamiranju u sportu u odnosu na učestalost posmatranja sportskih događaja tokom dana.

\section{Rezultati}

U prvoj tabeli su prikazani deskriptivni statistički podaci za sve tri tvrdnje koje su se odnosile na generalne stavove ispitanika prema reklamiranju u sportu. Prije svega, prikazana je aritmetička sredina koja oslikava pozitivne vrijednosti stavova kada su sve tri

Tabela 1. Generalni stavovi prema reklamiranju u sportu

\begin{tabular}{ccccccc}
\hline & \multirow{2}{*}{ Mean } & \multirow{2}{*}{ S.D. } & \multicolumn{2}{c}{ Skewness } & \multicolumn{2}{c}{ Kurtosis } \\
\cline { 4 - 7 } & & & Statistic & S.E. & Statistic & S.E. \\
\hline GSS1 & 4.71 & 2.109 & -.647 & .129 & -1.029 & .257 \\
GSS2 & 4.91 & 2.196 & -.795 & .129 & -.929 & .257 \\
GSS3 & 4.33 & 1.901 & -.404 & .129 & -1.132 & .257 \\
\hline
\end{tabular}

Legenda:Mean - Aritmetička sredina; S.D. - Standardna devijacija; Skewness - Mjera asimetrije; Kurtosis - Mjera spljoštenosti; Statistic - Statistička vrijednost; S.E. - Standardna greška; GSS1 - Moje opšte mišljenje je naklonjeno reklamiranju u sportu; GSS2 - Sveobuhvatno. smatram da je reklamiranje u sportu dobra stvar; GSS3 - Sveobuhvatno. da li ne volite ili volite reklamiranje u sportu

tvrdnje u pitanju, dok vrijednosti standardne devijacije pokazuju da elementi skupa, u prosjeku ne odstupaju značajno od arit- meticke sredine. Kada se govori o mjerama asimetrije (Skewness) i spljoštenosti (Kurtosis), negativne vrijednosti asimetrije

Tabela 2. Multivarijatna značajnost razlika u sistemu generalnih stavova prema reklamiranju u sportu kod ispitanika sa različitim navikama kada je posmatranja sportskih događaja u pitanju

\begin{tabular}{|c|c|c|c|c|}
\hline & & $\mathbf{N}$ & Mean & S.D. \\
\hline \multirow[t]{7}{*}{ GSS1 } & Ne posmatraju & 51 & 4.20 & 2.164 \\
\hline & $1-30$ & 115 & 4.81 & 1.854 \\
\hline & $31-60$ & 79 & 4.62 & 2.266 \\
\hline & $61-90$ & 44 & 3.93 & 2.297 \\
\hline & $91-120$ & 29 & 6.10 & 1.655 \\
\hline & $>120$ & 40 & 5.08 & 1.992 \\
\hline & Ukupno & 358 & 4.71 & 2.109 \\
\hline \multirow[t]{7}{*}{ GSS2 } & Ne posmatraju & 51 & 4.18 & 2.056 \\
\hline & $1-30$ & 115 & 4.94 & 2.053 \\
\hline & $31-60$ & 79 & 4.77 & 2.320 \\
\hline & $61-90$ & 44 & 4.50 & 2.547 \\
\hline & $91-120$ & 29 & 6.10 & 1.676 \\
\hline & $>120$ & 40 & 5.60 & 1.997 \\
\hline & Ukupno & 358 & 4.91 & 2.196 \\
\hline \multirow[t]{7}{*}{ GSS3 } & Ne posmatraju & 51 & 3.59 & 1.374 \\
\hline & $1-30$ & 115 & 4.30 & 1.807 \\
\hline & $31-60$ & 79 & 4.42 & 1.919 \\
\hline & $61-90$ & 44 & 4.16 & 2.068 \\
\hline & $91-120$ & 29 & 4.93 & 2.251 \\
\hline & $>120$ & 40 & 4.90 & 2.010 \\
\hline & Ukupno & 358 & 4.33 & 1.901 \\
\hline
\end{tabular}


kod svih promjenljivih pokazuju da je većina rezultata desno od srednje vrijednosti, među većim vrijednostima, dok negativne vrijednosti spljoštenosti kod svih promjenljivih pokazuje da je raspodjela pljosnatija od normalne tj. da ima više rezultata nagomilanih na repovima raspodjele.

U nastavku ove studije su prikazani komparativni statistički podaci generalnih stavova prema reklamiranju u sportu koji su dobijeni primjenom multivarijatne analize varijanse (MANOVA), univarijatne analize varijanse (ANOVA) i LSD Post Hoc testa, a u cilju utvrđivanja razlike u generalnim stavovima ispitanika prema reklamiranju u sportu u odnosu na učestalost po- smatranja sportskih događaja tokom dana.

Inspekcijom druge tabele u kojoj su prikazani rezultati multivarijatne analize, jasno se uočava da u cijelom sistemu upoređivanih parametara postoji statistički značajna razlika u generalnim stavovima prema reklamiranju u sportu u odnosu na učestalost posmatranja sportskih događaja tokom dana $(\mathrm{p}=.000)$.

Inspekcijom treće tabele $u$ kojoj su prikazani rezultati univarijatne analize, jasno se uočava da je, takođe došlo do statistički značajnih razlika u generalnim stavovima prema reklamiranju u sportu u odnosu na posmatranje sportskih događaja kod sve tri promjenljive.

Tabela 3. Univarijatna značajnost razlika u sistemu generalnih stavova prema reklamiranju u sportu kod ispitanika sa različitim navikama kada je posmatranje sportskih događaja u pitanju

\begin{tabular}{ccc}
\hline & $\mathbf{F}$ & $\mathbf{p}$ \\
\hline GSS1 & 4.908 & .000 \\
GSS2 & 4.193 & .001 \\
GSS3 & 3.044 & .011 \\
\hline
\end{tabular}

Inspekcijom naredne tri tabele gdje su prikazani rezultati Post Hoc testa koji ukazuju na značajnost razlika između parova pojedinačnih entiteta sa različitim navikama kada je posma-

tranje sportskih događaja u pitanju za svaku promjenljivu. Po rezultatima koji su se pojavili na univarijatnom nivou, očekivano uočavamo statistički značajne razlike pojedinih parametara.

Tabela 4.Utvrđivanje značajnih razlika u sistemu generalnih stavova prema reklamiranju u sportu primjenom Post Hoc testa između pojedinačnih entiteta sa različitim navikama kada je posmatranje sportskih događaja u pitanju kod tvrdnje „,moje opšte mišljenje je naklonjeno reklamiranju u sportu“"

\begin{tabular}{cccccc}
\hline vs & Ne posmatraju & $\mathbf{1 - 3 0}$ & $\mathbf{3 1 - 6 0}$ & $\mathbf{6 1 - 9 0}$ & $\mathbf{9 1 - 1 2 0}$ \\
\hline $1-30$ & .077 & & & & \\
$31-60$ & .251 & .530 & & & \\
$61-90$ & .532 & .017 & .076 & & \\
$91-120$ & .000 & .003 & .001 & .000 & \\
$>120$ & .043 & .480 & .255 & .011 & .041 \\
\hline
\end{tabular}

Došlo se do zaključka da se kod prve tvrdnje ,moje opšte mišljenje je naklonjeno reklamiranju u sportu“ javljaju razlike između ispitanika koji posmatraju sportske događaje između 91-120 minuta i svih ostalih entiteta; između ispitanika koji posmatraju sportske događaje od jednog do 30 minuta i onih grupa ispitanika koji sportske događaje posmatraju 61-90 minuta i 91-120 minuta dnevno; između

ispitanika koji posmatraju sportske događaje između više od 120 minuta dnevno i onih grupa koje ne posmatraju, koji ih posmatraju između 61-90 i 91-120 minuta dnevno. Možemo uočiti da pripadnici grupa koje posmatraju sportske događaje više od 91 minut imaju više pozitivne odgovore, dok najmanje pozitivnih rezultata vidimo kod grupe koja posmatra sportske događaje 61-90 minuta dnevno.

Tabela 5. Utvrđivanje značajnih razlika u sistemu generalnih stavova prema reklamiranju u sportu primjenom Post Hoc testa između pojedinačnih entiteta sa različitim navikama kada je posmatranje sportskih događaja u pitanju kod tvrdnje „sveobuhvatno, smatram da je reklamiranje u sportu dobra stvar"

\begin{tabular}{cccccc}
\hline vs & Ne posmatraju & $\mathbf{1 - 3 0}$ & $\mathbf{3 1 - 6 0}$ & $\mathbf{6 1 - 9 0}$ & $\mathbf{9 1 - 1 2 0}$ \\
\hline $1-30$ & .036 & & & & \\
$31-60$ & .124 & .595 & & & \\
$61-90$ & .465 & .250 & .501 & & \\
$91-120$ & .000 & .010 & .005 & .002 & \\
$>120$ & .002 & .095 & .048 & .020 & .337 \\
\hline
\end{tabular}

Došlo se do zaključka da se kod druge tvrdnje ,sveobuhvatno, smatram da je reklamiranje u sportu dobra stvar" javljaju razlike prije svega između ispitanika koji posmatraju sportske događaje između 91-120 minuta dnevno i svih ostalih entiteta. Takođe razlike se javljaju između ispitanika koji ne posmatraju sportske događaje uopšte i većine ostalih entiteta. Na kraju, raz-

like se takođe javljaju između ispitanika koji posmatraju sportske događaje više od 120 minuta i većine ostalih entiteta. Možemo uočiti da pripadnici grupa koje posmatraju sportske događaje više od 91 minut imaju najviše pozitivne odgovore, dok pripadnici grupe koja ne posmatraju sportske događaje uopšte imaju najmanje pozitivne odgovore.

Tabela 6. Utvrđivanje značajnih razlika u sistemu generalnih stavova prema reklamiranju u sportu primjenom Post Hoc testa između pojedinačnih entiteta sa različitim navikama kada je posmatranje sportskih događaja u pitanju kod tvrdnje „sveobuhvatno, da li ne volite ili volite reklamiranje u sportu“"

\begin{tabular}{cccccc}
\hline vs & Ne posmatraju & $\mathbf{1 - 3 0}$ & $\mathbf{3 1 - 6 0}$ & $\mathbf{6 1 - 9 0}$ & $\mathbf{9 1 - 1 2 0}$ \\
\hline $1-30$ & .024 & & & & \\
$31-60$ & .014 & .679 & & & \\
$61-90$ & .140 & .662 & .464 & & \\
$91-120$ & .002 & .109 & .208 & .086 & \\
$>120$ & .001 & .084 & .186 & .071 & .946 \\
\hline
\end{tabular}


Došlo se do zaključka da se kod treće tvrdnje „sveobuhvatno, da li ne volite ili volite reklamiranje u sportu“" pojavljuju razlike između ispitanika koji ne posmatraju sportske događaje uopšte i svih ostalih entiteta, osim grupe ispitanika koji posmatraju sportske događaje 61-90 minuta dnevno. Možemo uočiti da pripadnici grupa koje posmatraju sportske događaje više od 91 minut imaju najviše pozitivne odgovore, dok pripadnici grupe koja ne posmatraju sportske događaje uopšte imaju najmanje pozitivne odgovore.

\section{Diskusija}

S obzirom da su rezultati pokazali da ispitanici imaju veoma pozitivan stav prema reklamiranju u sportu što potvrđuje visoka vrijednost aritmetičke sredine za sve tri promjenljive, kao i da skoro dvije trećine ispitanika imaju pozitivan stav prema reklamiranju u sportu što se ogleda u izrazito negativnim vrijednostima mjera asimetrije, trebalo bi naglasiti da su ovi rezultate usaglašeni sa rezultatima prethodnih istraživanja (Bjelica, i Popović, 2011; Popović, 2011b; Popović, Molnar, i Radovanović, 2011 a; Popović, Matić, Milašinović, Jakšić, \& Bjelica, 2015a; Popović, Matić, Milašinović, Hadžić, Milošević, \& Bjelica, 2015b; Popović, Matić, Milašinović, Vujović, Milošević, \& Bjelica, 2015c), i da ne postoje značajne razlike koje bi trebalo pomenuti. Dobijeni rezultati, takođe jasno ukazuju da ispitanici koji žive na različitim lokacijama, kao što su Sjedinjene države, Turska, Crna Gora, Srbija i Bosna i Hercegovina, imaju pozitivne stavove prema reklamiranju u sportu, dok je, ipak, poređenja radi, vrijedno navesti da prema Mittal-u (1994), različite studije ukazuju na negativne stavove kada je reklamiranje proizvoda $\mathrm{u}$ tradicionalnim industrijama u pitanju. Prema tome, više je nego evidentno da je primjena sporta u savremenoj poslovnoj komunikaciji uticala da se generalni stavovi potrošača značajno promijene kada je reklamiranje u pitanju, a prepoznavanje privlač-

\section{R E F E R E N C E S}

Bjelica, D., i Popović, S. (2011). Stavovi potrošača prema reklamiranju u sportu u odnosu na učestalost posmatranja sportskih događaja. Sportske nauke i zdravlje, 1(2), 114119.

Bjelica, D., Popović, S., \& Akpinar, S. (2014a). Book of Abstracts of the 11th International Scientific Conference on Transformation Process in Sport "Sport Performance". Podgorica: Montenegrin Sports Academy.

Bjelica, D., Popović, S., Jakšić, D., Hadžić, R., \& Akpinar, S. (2014b). How Does Advertising through Sport Work? Evidence from Turkey. In Proceedings book of the 7th International Scientific Conference on Kinesiology "Fundamental and Applied Kinesiology - Steps Forward" (477). Opatija: University of Zegreb, Faculty of Kinesiology.

Bjelica, D., \& Popović, S. (2015a). Evolucija reklamiranja sa posebnim osvrtom na reklamiranje u sportu. Sport Mont, 13(43,44,45), 35-41.

Bjelica, D., \& Popović, S. (2015b). Evolution of Advertising with a Specific Retrospection at Sport Advertising. In Book of Abstracts of the 12th International Scientific Conference on Transformation Process in Sport "Sport Performance" (60-61), Podgorica: Montenegrin Sports Academy.

Bjelica, D., Popović, S., \&Akpinar, S. (2015c). Book of Abstracts of the 12th International Scientific Conference on Transformation Process in Sport "Sport Performance". nosti sporta je omogućilo poslovnim organizacijama da se približe sportskim potrošačima i na mnogo bezbolniji način utiču na njihovo ponašanje. Utvrđivanjem razlike u generalnim stavovima ispitanika prema reklamiranju u sportu u odnosu na posmatranje sportskih događaja tokom dana, u ovoj studiji su pronađene razlike u stavovima između ispitanika koji imaju različite navike kada je posmatranje sportskih događaja tokom dana $u$ pitanju. Ove razlike su se pojavile kod svih promjenljivih na univarijatnom nivou. Kod promjenljive „,moje opšte mišljenje je naklonjeno reklamiranju u sportu“, uočavamo da pripadnici koji posmatraju sportske događaje 61-90 minuta dnevno imaju najnegativnije stavove. Kod promjenjive „sveobuhvatno, smatram da je reklamiranje u sportu dobra stvar" i ,sveobuhvatno, da li ne volite ili volite reklamiranje u sportu“", ispitanici sa jednog entiteta tj. onih koji ne posmatraju sportske događaje imaju najnegativnije stavove.

Interesantno je istaći da su pronađene značajne razlike između potrošača koji posmatraju sportske aktivnosti u različinim vremenskim intervalima, što je bio slučaj u prethodnim studijama (Molnar, Lilić, Popović, Akpinar, \& Jakšić, 2011; Popović, Jakšić, Matić, Bjelica, \& Maksimović, 2014; Popović, Bjelica, Georgiev, \& Akpinar, 2011b; Popović, Matić, Milašinović, Jakšić, \& Bjelica, 2015d; Popović, Matić, Milašinović, Hadžić, Milošević, \& Bjelica, 2015e; Popović, Matić, Milašinović, Vujović, Milošević, \& Bjelica, 2015f; Popović, Jakšić, Matić, Bjelica, \& Maksimović, 2015g). Ovi rezultati su veoma važni za poslovne subjekte u Bosni i Hercegovini ali i za naučnu javnost, uglavnom iz razloga što ne mogu spojiti sve potencijalne potrošače koji posmatraju sportske aktivnosti u različinim vremenskim intervalima u jednu homogenu grupu, što se slaže sa prethodnim istraživanjima (Bjelica, Popović, Jakšić, Hadžić, \& Akpinar, 2014b; Bjelica, \& Popović, 2015a; Bjelica, \& Popović, 2015b; Bjelica, Gardasevic, Vasiljevic, \& Popovic, 2016a; Bjelica, Gardašević, Vasiljević, \& Popović, 2016c).

Podgorica: Montenegrin Sports Academy.

Bjelica, D., Gardašević, J., Vasiljević, I., \& Popović, S. (2016a). Ethical Dilemmas of Sport Advertising. Sport Mont, 14(3), 41-43.

Bjelica, D., Popović, S., \&Akpinar, S. (2016b). Book of Abstracts of the 13th International Scientific Conference on Transformation Process in Sport "Sport Performance". Podgorica: Montenegrin Sports Academy.

Bjelica, D., Gardašević, J., Vasiljević, I., \& Popović, S. (2016c). Ethical dilemmas of sport advertising. In Book of Abstracts of the 13th International Scientific Conference on Transformation Process in Sport "Sport Performance" (41), Podgorica: Montenegrin Sports Academy.

Bjelica, D., Popović, S., \& Akpinar, S. (2017). Book of Abstracts of the 14th International Scientific Conference on Transformation Process in Sport "Sport Performance". Podgorica: Montenegrin Sports Academy.

Gardašević, J., Zorić, G., \& Mašanović, B. (2017). Attitudes of Turkish consumers toward advertising through sport among the question how often they participate in sports activities. Journal of Anthropology of Sport and Physical Education, 1(1), 23-27.

Gardašević, J., Zorić, G., \& Mašanović, B. (2018). Attitudes of Montenegrin consumers toward advertising through sport among the question how often they participate in sports ac- 
tivities. Journal of Anthropology of Sport and Physical Education, 2(1), 15-19.

Klačar, M., i Popović, S. (2010). Reklamiranje u sportu kao efektivno sredstvo savremene komunikacije. Teme, 4, 12191230.

Mašanović, B., Zorić, G., \& Gardašević, J. (2017). Attitudes of Turkish consumers toward advertising through sport among the frequency of watching sports events. Journal of Anthropology of Sport and Physical Education, 1(1), 3-7.

Mašanović, B., Zorić, G., \& Gardašević, J. (2018). Attitudes of Montenegrin consumers toward advertising through sport among the frequency of watching sports events. Journal of Anthropology of Sport and Physical Education, 2(1), 9-13.

Molnar, S., Lilić, Lj., Popović, S., Akpinar, S., \& Jakšić, D. (2011). Attitudes of various demographic groups toward advertising through sport at METU. Facta Universitatis, Series: Physical Education and Sport, 9(3), 255-263.

Muratović, A., Bjelica, D., \& Popović, S. (2014). Examining beliefs and attitudes toward advertising through sport among montenegrin consumers. Facta Universitatis, Series: Physical Education and Sport, 12(2), 95-104.

Popovic, S. (2011). Reklamiranje u sportu kao efektivno sredstvo savremene poslovne komunikacije. Neobjavljena doktoska disertacija, Novi Sad: Univerzitet u Novom Sadu.

Popović, S. (2011b). Stavovi potrošača prema reklamiranju u sportu u odnosu na učestalost kupovine sportskih proizvoda. Sport Mont, 9(28,29,30), 140-147.

Popović, S., Molnar, S., i Radovanović, D. (2011a). Stavovi potrošača prema reklamiranju u sportu u odnosu na učestalost bavljenja sportskim aktivnostima. Sport Mont, 9(28,29,30), 148-155.

Popović, S., Bjelica, D., Georgiev, G., \& Akpinar, S. (2011b). Comparison of attitudes toward advertising through sport between Montenegrin and Turkish stakeholders. In Proceedings book of the 6th International Scientific Conference on Kinesiology "Integrative Power of Kinesiology" (612). Opatija: University of Zegreb, Faculty of Kinesiology.

Popović, S., Jakšić, D., Matić, R., Bjelica, D., \& Maksimović, N. (2014). Examining Beliefs and Attitudes toward Advertising through Sport among Serbian Consumers. In Book of abstracts of International conference "Economics and Management of Sports 2014” (pp. 11-12). Brno: Faculty of Sports Studies.

Popović, S., Bjelica, D., Jakšić, D, \& Georgiev, G. (2013). How does Advertising Through Sport Work? Evidence from Montenegro. In Book of Abstracts of the $18^{\text {th }}$ Annual Congress of the European College of Sport Science (444-445), Barcelona: National Institute of Physical Education of Catalonia.

Popović, S., Matić, R., Milašinović, R., Jakšić, D., \&Bjelica, D. (2015a). Stavovi srbijanskih potrošača prema reklamiranju u sportu u odnosu na učestalost bavljenja sportskim aktivnostima. Sport Mont, 13(43,44,45), 50-56.

Popović, S., Matić, R., Milašinović, R., Hadžić, R., Milošević, Z. \& Bjelica, D. (2015b). Stavovi srbijanskih potrošača prema reklamiranju u sportu u odnosu na učestalost kupovine sportskih proizvoda. Sport Mont, 13(43,44,45), 262-269.

Popović, S., Matić, R., Milašinović, R., Vujović, D., Milošević, Z. \& Bjelica, D. (2015c). Stavovi srbijanskih potrošača prema reklamiranju u sportu u odnosu na učestalost posmatranja sportskih događaja. Sport Mont, 13(43,44,45), 270-276.

Popović, S., Matić, R., Milašinović, R., Jakšić, D., \& Bjelica, D. (2015d). Attitudes of Serbian Consumers toward Advertising through Sport among the Question How Often They Participate in Sports Activities. In Book of Abstracts of the 12th International Scientific Conference on Transformation Process in Sport "Sport Performance" (58-59), Podgorica: Montenegrin Sports Academy.

Popović, S., Matić, R., Milašinović, R., Hadžić, R., Milošević, Z., \& Bjelica, D. (2015e). Attitudes of Serbian Consumers toward Advertising through Sport among the Question How Often Consumers Purchase Sporting Goods. In Book of Abstracts of the 12th International Scientific Conference on Transformation Process in Sport "Sport Performance" (5960), Podgorica: Montenegrin Sports Academy.

Popović, S., Matić, R., Milašinović, R., Vujović, D., Milošević, Z., \& Bjelica, D. (2015f). Attitudes of Serbian Consumers toward Advertising through Sport among the Frequency of Watching Sports Events. In Book of Abstracts of the 12th International Scientific Conference on Transformation Process in Sport "Sport Performance" (60), Podgorica: Montenegrin Sports Academy.

Popović, S., Jakšić, D., Matić, R., Bjelica, D., \& Maksimović, N. (2015g). Examining Beliefs and Attitudes toward Advertising through Sport among Serbian Consumers. Studia Sportiva, 9(1), 225-231.

Popović, S. (2015). Sport Nowadays (In Montenegrin). In D. Bjelica (Ed.), Advertising Role of Sponsorship in Modern Sport (pp. 111-116). Podgorica: Montenegrin Sports Academy.

Popović, S. \& Milašinović, R. (2016). Model of Advertising Communication in Sport. Sport Mont, 14(1), 33-38.

Zorić, G., Mašanović, B., \& Gardašević, J. (2017). Attitudes of Turskish consumers toward advertising through sport among the question how often consumers purchase sporting goods. Journal of Anthropology of Sport and Physical Education, 1(1), 17-21. doi: 10.26773/jaspe.171003

Zorić, G., Mašanović, B., \& Gardašević, J. (2018). Attitudes of Montenegrin consumers toward advertising through sport among the question how often consumers purchase sporting goods. Journal of Anthropology of Sport and Physical Education, 2(1), 21-25.

\author{
I. Bajramovic \\ University of Sarajevo, Faculty for Sport and Physical Education, Patriotskelige 41, 71000 Sarajevo, Bosnia and Herzegovina \\ e-mail: bajramovic.izet@gmail.com
}


